\title{
SENDAS ROTAS: LA METAFÍSICA COMO FUGA METAFÓRICA HACIA EL SER DE FENÓMENO
}

\section{BROKEN PATHS: METAPHYSICS AS A METAPHORICAL FLIGHT TOWARDS THE BEING OF PHENOMENON}

\author{
VICENTE LLAMAS ROIG \\ Pontificia Universidad Antonianum (Murcia)
}

Recibido: $17 / 11 / 2018 \quad$ Aceptado: 23/01/2019

\section{RESUMEN}

La metafísica en la era de alienación transcendente (período orgánico de la historia del pensamiento occidental dominado por la expectativa de un destino gnoseomórfico superior -espejismo de un superyo accedente al metafenómeno de ser-) es sierva del símbolo (signo en función metasémica), tanto como la anti-metafísica (post-nietzscheana) era del ello, en su adicción al icono (signo del epílogo que postra al sujeto en una radical inmanencia alienante), pueda ser esclava de las máscaras morfológicas de esa facción psíquica. Una posible revitalización de la metafísica pasaría por la instrumentación de la metáfora ontológica como figura transpositiva del fenómeno de ser en su pulsión óntica pura, el ser de fenómeno. Tal es la propuesta de este ensayo.

Palabras clave: alienación, fenómeno, signo, metáfora ontológica.

\section{ABSTRACT}

Metaphysics in the age of transcendent alienation (organic period in the history of western thought ruled by the prospect of a superior gnoseomorphic fate -mirage of a superego that tries to reach the meta-phenomenon of being) works as the servant of the symbol (sign in meta-semic function), likewise the anti-metaphysical (post-Nietzschean) era of the id, by its addiction to the icon (evidence of the epilogue that leaves 
the subject prostrate under a drastic alienating immanence), may be the slave of the morphological masks of that psychic feature. A possible renewal of metaphysics would entail the instrumentation of the ontological metaphor as a transposition figure of the phenomenon of being in its pure ontic basis, the being of phenomenon. Such is the proposal of this essay.

Keywords: alienation, phenomenon, sign, ontological metaphor.

\section{DIAGNOSIS: LA METAFÍSICA EN LA ERA DEL ELLO}

La desacreditación epistemológica de la metafísica como saber eminente, aun al servicio secular de una razón alienada por adicción transcendental, estriba en su dolosa aplicación como medio de rectificación "óptica": lente pretendidamente correctora de la anomalía congénita de convergencia de un noûs amétrope que falsea el campo epistémico remoto, horizonte nouménico inaccesible naturalmente a esa inteligencia privada de capacidad intuitiva intelectual, en forma de campo imaginal comprendido entre objetivos fenoménico y meta-fenoménico, que acotarán precisamente el dominio cognitivo de ese noûs genéticamente aquejado del defecto de visión apuntado. Una fraudulenta aproximación óptica del objeto remoto (meta-epistémico) en calidad imaginal (simbólica, analógica, ... ).

El símil óptico establecido ejemplifica el uso de la metáfora ontológica como herramienta primordial de la metafísica que el ensayo propone. Esa metáfora, por su misma condición (ontológica), trans- (meta-) pone (-phorá) el fenómeno de ser, objeto ontológico (fenomenología), al plano de su fundamento óntico puro (ser de fenómeno), motivo metafísico basal.

Las tres sendas de la sospecha desembocan en la alienación porque confluyen en el ello, facies o expresión psíquica relevante del zoôn hedonikón, subfenotipo eikonófago emergente del alienado zoôn cosmo-poietikón adicto al icono, vector de alienación inmanente como el símbolo abrazado por el zoôn theopoietikón lo fuera de alienación transcendente. Las diversas variantes de filosofía de la sospecha reniegan de la alienación transcendente que marca la era glacial del super-yo represor para incurrir en una forma alienante de completo abandono activo al devenir (devenir: despliegue inmanente del ser en el kósmos horatós), encubriendo bajo la máscara morfológica del yo las pulsiones subterráneas del ello (el pre-moderno "ego conquiro" que impone unilateralmente desde su esfera vital la propia subjetividad y las condiciones de diálogo al otro -noego-, conquistado en acto según una praxis de la dominación sustentada en una 
racionalidad discriminativa", o el moderno "ego cogito" que supera la duda primordial autoafirmándose en la línea metafísica del Exxodo como ser -pensante-, viran al "ego volo" / "ego requiro" / "ego desidero" / "ego habeo" y otras tantas variaciones predicativas que abisman al yo en las pulsiones ilúdicas, agostándole o hipotecándole en la pura inmanencia). La alienación de la poíesis reificada por expropiación del producto en el que se proyecta esencialmente el Homo faber, el enano teológico (ello) soterrado en el marxismo, delatan el relevo de la pístis (super-yo) y la nóesis (yo) por la poíesis que, englobando a la segunda (ideogénesis como actividad productiva: poíesis endergónica -érgon interno a la poíesis- frente a la acción exergónica transitiva -érgon externo-), procura esencia a una subjetividad originariamente vacía, sin guiones o excusas naturales, y, al fin, el moderno terapeuta se erige en el nuevo filósofo, casi investido de dignidad sacerdotal, presto a rescatar de las sombras a angustiados, neuróticos, deprimidos o compulsivos reos, siempre manejando conjuros de una era fluida, refractaria a la culpa u otros sedimentos obstructivos del curso fluvial (el kósmos noetós en que gravita el super-yo opresor transfigurado por inversión de prelación relativa de mundos en la claustrofóbica caverna de metafisemas, categorías caducas, fosa de signos antinaturales gestados en retrogénesis traumáticas), para apelar a un yo impostado, no verdaderamente tutelar, mermado por afluencia kárstica del psiquismo instintivo.

En su doble faz, el lógos mira ad aliud (un aliud o alienum supra se o infra se, en la estela del dualismo cósmico ancestral: kósmos noetós / kósmos aisthetós, el alma anfibia en su pulsión sensible o noética). La inflexión entre las dos vertientes de esa dual vocación ad extra es el momento intra se de génesis del yo, y en la cualidad de la mirada ad alienum reside el riesgo de la alienación, transcendental (abducción ad supra, con ferviente pretensión de hallazgo epistémico de verdades estables que elevan al yo en su abducción a la condición de superyo; naufragio en ilusorios absolutos, en un ideal o ficción transcendente, que,

1 El "ego conquiro" se señorea en la protohistoria de la constitución del "ego cogito" sobre una dialéctica de la dominación [dialéctica centro-periferia, lugar de consolidación del dominio, observa Dussel: universalidad descubridora / particularidad sitiada. Cf. Enrique Dussel, El encubrimiento del otro. Hacia el origen del mito de la modernidad (La Paz: Plural Edit., 1994), 36-47] que niega la subjetividad inicial del conquistado, objetualizado (ser sin conciencia de víctima por considerar su praxis sólo una disposición activa conforme a la ley natural) hasta la incorporación de los valores culturales centrales que le aseguren una esfera vital de propiedad, aun periférica. El ego arraigado en el Viejo Mundo enfrentado al no-ego del Nuevo, el indígena cosificado respecto al que se arroga legitimidad civilizadora, $\sin$ Lebenswelt propio (la colonización ofrece una oportunidad ontológica única al sujeto pre-moderno para la auténtica egomorfosis en cuanto figura humanizadora, "infusora" de imagen y semejanza al sometido para una gradual subjetivación, portadora de valores culturales y religiosos a transmitir: la constitución del "ego conquiro" preludia la emergencia del "ego cogitans", y es en sí un proceso ontológico, soberanía de un ser ya cristalizado como ego en su eigensphäre o en su mundo vital sobre otro que no lo está, noegoforme. 
asumida como real, determina estructuras y condiciones de vida antes del supraegocidio místico, el hundimiento por unio mystica en la divinidad colapsante) o inmanencial (ad infra, un lógos aferrado al mundo sensible que ha perdido la ilusión transcendente, apenas acuciado por lívidos anhelos, una pálida inquietud de cauces borrosos sofocada por la magia de la ciencia o eclipsada por la taumaturgia de la tecnología). El giro subjetivista del idealismo y la parusía del absoluto son decisivos en la declinación irracional del noúmeno, rift o falla gravitacional hacia la anástrofe cósmica: ingénitas categorías kantianas frente a autopoyéticas categorías fichteanas, interacción universal y síntesis "yo" / "no-yo" (esa síntesis con el "no-yo" auspicia la abrupta emersión del ello por exilio del noúmeno de la conciencia cognitiva -objeto de thígein kaì phánai más que de légein, "tocar" desvelante más que "decir" vulnerante) y dependencia de la autoconciencia en su existencia como fenómeno social de los objetos del mundo extra se, aun cuando la percepción de los mismos sea, a su vez, dependiente de la existencia de la conciencia ${ }^{2}$ ). Lo sagrado halla refugio en la filosofía. Si la modernidad lo ha profanado todo -en la visual hegeliana-, si todo es ya objeto de un conocimiento "muerto, historizante" (tote, historische Kenntnis, un craso raciocinio -kahlen Räsonnement-), la filosofía debe convertirse en un "estamento sacerdotal aislado - un lugar sagrado" (Priesterstand isoliert - Heiligtum) para ser custodia o tomar posesión de la verdad. El ab-solutum pervive como lo separado, fugitivo de la razón, se entrega sólo a la imaginación. El pulso mythoslógos escora hacia el primero con el romanticismo, este movimiento se decanta por el mythos como una actitud imaginativa respecto a la phýsis, el retorno al orden natural desde la herida de la razón ${ }^{3}$.

$\mathrm{Y}$ así, se perfilan las eras del espíritu en el enigma de la esfinge ${ }^{4}$. Del

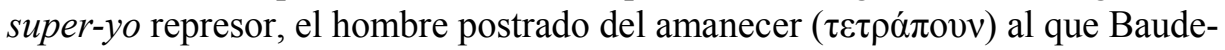
laire contemplara en luctuoso cortejo, doblegado por la quimera prendida con las garras al pecho, impulsado por una irresistible necesidad de caminar hacia

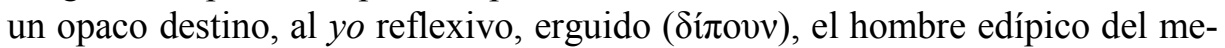
diodía que ha superado la minoría de edad de la razón para encontrarse a sí

2 La paradoja de Fichte, soluble sólo con la adquisición de conciencia por un ser racional en su invocación como consciente por otro fuera de sí. Relación de derecho en el mutuo reconocimiento de conciencia o de racionalidad.

3 Mythos y lógos reflejan dos actitudes distintas ante la phýsis, dos formas de mirada diferentes hacia ella. Mythos, una actitud narrativa, la del relato epigenético que diviniza las fuerzas cósmicas, dejando al hombre a merced de las veleidades de dioses caprichosos. Lógos, ya no una actitud descriptiva o narrativa, sino explicativa, un sondeo abstracto que busca la regularidad genética, fenoménica, el nómos interno (concepción heraclitea del lógos como ley interna a la phýsis, norma dialéctica de devenir). El lógos tiende una mirada elementalista al arjé, busca un principio indeterminado original (tó ápeiron), y al fin, el ser estable en detrimento de la mudable apariencia.

4 Vicente Llamas, El lógos bifacial. Las sendas de Éros y Thánatos (Madrid-Porto: Sindéresis, 2015), 21 ss. 
mismo, ambos criaturas bifaciales que miran de diferente manera al mundo

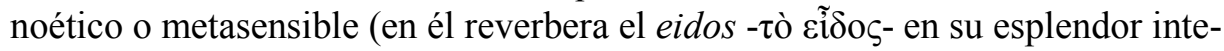
ligible de noetón para el primero, depuesto por el segundo bajo la incognoscibilidad del noúmeno, excedente de la capacidad de intuición humana, despojado de valor epistémico al desmarcarse de las competencias del entendimiento, mas no de la razón pura como ficción racional de carácter normativo, o aliciente de una razón estética), y finalmente, del incisivo errante de pies hinchados al hombre crepuscular, dominado por el ello instintivo y el sentido trófico (irracional) del noúmeno, apegado al mundo sensible del atardecer desde el que la próvida techné, en principio auxiliar, benefactora (fase prometeica de subordinación de la techné al lógos), dicta su epílogo tras absorber perversamente al lógos (fusión tehné-lógos: lógos monofacial) ofreciendo ilimitadas promesas de éxtasis lúdico a través de escenarios virtuales, suplentes de los alienantes itinerarios teofánicos del hombre reverente, en los que va madurando un animal distinto que habrá sustancializado el elemento tecnológico, un apéndice co-extensivo a su naturaleza ( $\tau \rho i ́ \pi o v v)$, no accesorio: el hombre post-prometeico de identidad fisurada. Este peso no inerte, envolvente, es tan alienante como el de la abrumadora quimera que atenaza al hombre encorvado del poema de Baudelaire, la arrastra sin irritación alguna (rostro fatigado, ninguna desesperación mostraba, hundidos los pies en el polvo de la vasta llanura sin sendas ni ortigas ni hierba, tan desolada como el cielo mismo, caminando con la faz resignada del condenado a esperar siempre), el furioso monstruo que le oprimía y al que parecía considerar parte de sí mismo, no un nocivo parásito.

Las tres vías de la sospecha conducen en su radicalización a la postmodernidad antidualista, incrédula, reacia a la teleología emancipativa de las vanguardias, reino fracturado del animal ilúdico, de la cultura fraccionada, sin auténtica cosmovisión, suprimida toda forma de utopía, derruido el ideal transcendente por la erosión del relativismo líquido que propicia una perspectiva no inercial de referencia, sin incondicionados, focal de consenso axiológico en la acción comunicativa libre de imperativos categóricos que dinamicen éticas autónomas de universales. Livianas éticas democráticas, minimalistas, de vocación global, no universal, por ausencia de meta-narraciones, y la religión del ocio que reduce el individuo a dato anónimo como telón de fondo. Los ídolos baconianos del foro o de la caverna acechan sigilosamente.

Si la era ácima fue esclava de un pacto de vida fría (Mann) a través del que se vislumbra (teorema de Thomas) el efecto real de la vivencia de un ideal transcendente como si fuera real (alienación) -pirámide feudal, volutas o envolturas sociales replicantes de la jerarquía celeste ...-, la era ilúdica es sierva del Estado total surgido de un empañado ideal burgués y de la conmoción de una revolución 
industrial enajenante que acabarán por sacrificar la paideia a la hipnopedia, la reflexiva autodeterminación de la acción volitiva, dignificante del individuo en su adhesión personal a un sistema de valores, a los vacilantes renglones de una voluntad sonámbula, convertido el zoôn poietikón, hechizado por el icono, en voraz devorador de sombras (zoôn eikonikón) que repelen la acción metafísica.

\section{PROLEGÓMENOS A UNA (INCIERTA) METAFÍSICA FUTURA}

Proposiciones que sustentan una ontología fenomenológica post-sartreana como dominio original de aplicación de la metáfora:

I. Mundo, en su dimensión ontológica, es el conjunto de fenómenos que acaecen.

II. Lo ontológico es el fenómeno de ser. Toda ontología es, pues, fenomenológica.

III. El fenómeno de ser se significa como tal para una conciencia sobre la que recae, entonces, la función ontológica, y respecto a la que el mundo se constituye ontológicamente en su mundo.

Corolario III.1: Mundo es el conjunto de fenómenos que acaecen en torno a un para-si fundante.

IV. La ensidad óntica pura del fenómeno de ser es transfenoménica, exigencia de la fenomenalidad del ser. El ser de fenómeno no es nooúmenon sino fundamento óntico de fenómeno de ser, tiene viso ontológico neto como fenómeno de ser, sin zonas obturadas, una faz velada, sustraída al phaínein, si bien no podría ser residuo fenomenológico, únicamente matriz metafenoménica del fenómeno de ser.

Corolario IV.1: no hay ser de metafenómeno sino ser metafenoménico de fenómeno (dado que la metafenomenalidad o ensidad del ser es exigencia del fenómeno de ser, la negación del ser de metafenómeno anula el metafenómeno de ser).

V. El ser de fenómeno no se agota ontológicamente en ninguna concreta manifestación como fenómeno de ser, sólo es plenum de ensidad óntica que fundamenta la posibilidad ontológica misma del fenómeno de ser, a modo de término general de la serie potencial completa de apariciones (el en-sí óntico fundante de la misma posibilidad fenoménica abarca el espectro íntegro de potenciales manifestaciones). 
VI. La conciencia o ser-para-sí surge como hipocentro sémico de un mundo por negación de la propia fenomenalidad.

Corolario VI.1: El ser-para-sí aflora por abjuración de su propia posición ontológica como fenómeno de ser, en contraste a este, constituido en tal frente al para-sí. La conciencia sería nihil ontologicum para-sí misma o en cuanto ser-para-sí (negación del fenómeno de ser que él mismo fuese, negación sólo ontológica: "nada de ser" = "no-fenómeno de ser" para-sí en integridad), mas no nulidad óntica ( $\neq$ "no-ser de fenómeno") puesto que su propia ensidad (ser de fenómeno) escapa al control ontológico del para-sí, es condición externa a él, preservando su fenomenalidad respecto a otro para-sí (de no ocurrir esto, la detracción de la propia fenomenalidad que la conciencia se impone en irrupción como ser-para-sí la anularía ónticamente, por ser la ensidad requisito de la fenomenalidad del ser). Su ensidad, sobre la que adolece de poder más allá de la potestad de negación o aniquilación, es fundamento óntico de su fenomenalidad para otra conciencia.

Corolario VI.2: la competencia del ser-para-sí es ontologizadora (referencia ontológica no-inercial sin facultad sobre el tò hólos óntico prehabido en cuanto óntico), única función que el para-sí puede desplegar sobre sí como negación, o sobre lo óntico en general. La conciencia no es responsable del ser de fenómeno (no es creadora), sólo de su ontologización como fenómeno de ser configurante del campo ontológico envolvente del para-sí gestionado en la forma de (su) mundo-Eigenwelt(fundación del mundo por ontologización regional del plenum de ensidad óntica: "mundo" = "onto-sistema" fenomenológico o ámbito fenoménico temporal de un para-sí).

VII. La experiencia de la propia corporeidad y su proporción fenoménica supone un salir-fuera-de-sí, situándose a nula distancia de sí para afrontarse ontológicamente a sí. Esa eversión o kénosis pro-ontológica entraña un índice de extrañeza por disipación del para-sí, colapso egológico en la contracción ontológica del para-sí a fenómeno de ser.

Corolario VII.1: el para-sí, en cuanto tal para-sí, es nada fenoménica (no "en-sí" fenomenalizado) y es el interrogante sobre su propia nada de ser, la inquisición sobre su nulificación fenomenológica, el que puede sostener una metafísica, más allá de la ontología ceñida estrictamente al fenómeno de ser que el para-sí se niega a sí.

VIII. La metafísica es una no-ontología, un discurso no primo-intencional ajeno a claves relacionales fenomenológicas (causalidad, analogía, ...), relativo 
al ser de fenómeno. Las nociones vertebrales de cualquier ontología estarían desvirtuadas en su función significante, distorsión semiótica por remisión de signos a un fenómeno de ser bloqueado en la auto-referencia del para-sí, inmerso operativamente en su Eigenwelt, sumido en su esfera de propiedad ontológica, de ahí el carácter metafórico de toda transición entre fenómeno y ser de fenómeno.

IX. El signo en su primera intencionalidad (carga denotativa) remite al fenómeno de ser, siendo así vector ontológico. Toda fenomenología se sustenta sobre la primera intencionalidad o función denotativa (suppositio) del signo, su valor significativo natural, primario.

X. El en-sí óntico sólo admite la descripción analítica de ser que es lo que es.

XI. La metafísica solamente puede hacer referencia indirecta al fenómeno de ser por meta-intencionalidad del signo (función connotativa).

XII. El vehículo de trasposición del fenómeno de ser (ontológico) al ser de fenómeno (óntico) es la metáfora ontológica, instrumento adecuado a la metafísica.

XIII. Símbolo e icono redimensionan al signo en segunda significatividad (valor no denotativo, sin gravamen epistémico), medios de alienación transcendente (era teológica del super-yo) e inmanente (era del ello bajo máscara egomórfica).

XIV. Símbolo e icono convocan al meta- o epifenómeno de ser.

$\mathrm{XV}$. La proyección intencional del para-sí a lo otro de sí es un acto violento de penetración que vulnera la ensidad de la cosa, su ensimismamiento óntico, fenomenalizándola.

XVI. El índice de indiferencia gnoseológica ligado a cualquier epojé fenomenológica que aspire al eîdos autárquico de las cosas, a su semblante mismo, no está exento de la incertidumbre normativa de todo acto de conocimiento. El error fenomenológico no es pre-cognitivo, acompaña a la fundación ontológica de su mundo por un para-sí y se encuadra en la alteración que provoca el acto de observación. 


\section{EPÍGONOS DEL SÍMBOLO, VECTOR DE ALIENACIÓN TRANSCEN- DENTE EN LA ERA DEL SUPER-YO}

El símbolo abrió una perspectiva global de lectura sistemática de la compleja realidad del sacramento como medio de acción divina en el horizonte humano, una categoría antropo-teológica rescatada de la tradición eclesial que dinamizó la reflexión teologal a la luz del interrogante sobre la desconexión de la liturgia de la necesidad e inquietudes humanas en un marco temporal concreto.

En su etimología griega, el término "símbolo" alude a la unión o re-unión de partes $(\sigma u \mu \beta \alpha ́ \alpha \lambda \lambda \varepsilon v v)$, vector de identidad, de encuentro y reconocimiento, instrumento de cognición remota, más allá de la percepción sensible, base de un lenguaje indirecto, la cisura del doble sentido del signo sacramentológico en la hermenéutica de Ricoeur:

- Primer significante: sentido aparente del símbolo en su recta disponibilidad

- Segundo significante, referente de hipotética realidad figurada o espiritual, accesible desde el primero, que no es envoltura externa u ocasión para el acontecimiento del signo en segunda significación sino experiencia antropológica de él desde la realidad física ya como símbolo. El signo escondido aflora en la transición transcendente que procura el lenguaje simbólico: por el segundo significado, el signo se hace símbolo. El Hermano Sol o la Hermana Luna desvelan ese significado transcendente, no evocan la entidad física de los cuerpos celestes a que remiten los signos "Sol" o "Luna" sino una realidad de orden diverso.

En una teología de la transparencia, el segundo significado de las cosas, su dimensión simbólica y el sentido salvífico que transfunde, pasan por la función reveladora del símbolo, no la supositiva del signo en la primera significación que lo contrae a intención psíquica (virtud sémica suplente de la res extra animam). La segunda significación hará del signo un símbolo con papel vehicular, no atingencia directa, no el tendere in re del signum rei, ni la reminiscencia formal de un signum signi, sino una coyuntura meta-intencional como vicario teofánico. En el símbolo está contenida la materialidad del primer significado, a la que reenvía como signo, fugando por la segunda hacia una realidad transcendente.

El signo suple la realidad inmanente signada (significa o sustituye -stare pro aliquo- en su esse signum), el símbolo participa la realidad transcendente significada, plisa la materialidad intencionalizada en la primera significación, transcendiéndola en la segunda, portador de un significado espiritual, no puramente psíquico-intencional. El símbolo transluce la realidad contenida, no 
agotada, condensando aspectos sustantivos más densos y profundos de la existencia humana, presencia real en la ausencia física: la presencia material en el símbolo es indicio de ausencia porque transporta a una realidad superior, depositario de un plus de significado. El símbolo es "testigo de un lugar vacante", dicta la teología sacramental, el hueco ontológico que genera la transcendencia de la res como creatura subsidia la embajada meta-intencional del símbolo.

El símbolo es signo en sobrevaluación meta-significativa. El estatuto mediador del símbolo, a diferencia del papel supositivo del signo, no es el de una segunda intención, ni el de una categoría metafísica o lógica, sino un nexo entre primera y segunda significación, por esa mediación contiene lo que anuncia, ahí radica su solapada realidad metafísica frente a la simple referencia física del signo. El beso como signo evoca el acto físico de besar; como símbolo, "participa" la realidad metafísica del amor.

El símbolo es el soporte del meta-relato abolido en la visión de Lyotard sobre la tragedia postmoderna. Es signo recodificado meta-intencionalmente en segunda significatividad por cuanto despliega su función reveladora sobre una dimensión metafenoménica de lo real. La orfandad de meta-relatos haría del mundo ilúdico actual un orden anti-metafísico y anti-simbólico, En la confrontación dialéctica de elementos cohesivos y disgregantes, sim-bólicos y dia-bólicos, en liza por definir el perfil antropológico del fenotipo eikonikón (la lógica sombría y disociativa de los iconos -lógica ocre de la eikasía, variante de doxá tan peligrosa como la pístis-), el elemento fáustico domina la era del pacto de vida fría, la era del ello. La bidimensionalidad sémica del símbolo, apta sólo para un lógos bifacial, languidece. El lógos monofacial se muestra impotente ante la invitación del símbolo.

Si la era del super-yo se caracteriza por la devoción al símbolo como portal de acceso al kósmos ouranós (el yo alienado en adhesión a verdades superiores

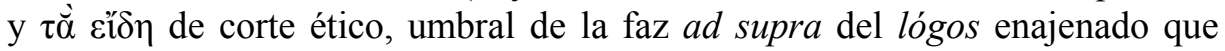
acabará por deshacerse de esa patología relegando al rol de incondicionados meta-cognitivos a los noetones constelares del campo de ensidad óntica, el campo nouménico en que deriva la utopía platónica de lo en-si), la era del ello, inaugurada por la anástrofe ontológica nietzscheana (inversión de privilegiada posición relativa de mundos: kósmos horatós primante, antinatural noetós decadente. La moral del lógos con sus referentes absolutos cede a la moral disidente, minimalista, del páthos), un enjambre de voluntades náufragas, libres de estáticas referencias inerciales, impelidas a tamizar una pseudo-subjetividad o una laxa subjetividad estética en marcos no inerciales de actuación y auto-realización (el espacio-tiempo contractivo-dilatativo del individuo atomizado -¿la raza 
hiperbórea, sin raíz intrahistórica, adversa al hombre moderno "que no sabe salir ni entrar"? ¿Es ese el fatum de plenitud, la hipertrófica fortaleza del sediento de rayos y de hechos contra la abnegación de los débiles sepultados en los derubios del dogma?-, no disipado en el alienante cuerpo de referencias hiperdensas, trenzadas en el tiempo primordial-espacio prológico y en el tiempo ultrahistórico-espacio escatológico, Urzeit y Endzeit del mito, pero tampoco prendido al ideal transcendente), es ajena al símbolo y adepta al icono. La lógica silenciosa, laminar, del símbolo pierde su vigor estático bajo la lógica desolada y turbulenta de la inmanencia, la lógica transcendente del símbolo cede a la lógica inmanente del icono en su vigor mutante; la lógica paciente, abisal, del persistente meta-relato, desplazada por la lógica urgente, inmediata, de iconos mudables, una logomaquia de fugaz vigencia en la que las sombras proyectan su vacía intencionalidad suplida por subliminales vectores hipnopédicos (no paidéticos) sobre conciencias sonámbulas (sueños ocres, permeables, en los que inocular mensajes sesgados, simplificativos), alentando su vocación de superficie y alimentando la sed de vida estética.

Dos formas de lógos alienado por meta-narración o hipnopedia, entonces. El icono es el signo unidimensional (lógos monofacial) perversamente transvaluado (Umwertung der Werte) por redirección epifenoménica, sólo una punción significativa sin la carga meta-epistémica del signo, la función mediadora que procura la segunda significación. Una nueva moral de esclavos, ahora no de resentimiento contra todo lo vital desde la ruptura del equilibrio entre elementos apolíneos y dionisíacos forjado en el orden griego, sino contra todo absoluto fraguado en un marco de idealismo transcendental; una nueva moral (democrática) de renuncia, no a la vida postrada ante un falso trasmundo y basada en el símbolo, sino al subsuelo de la auténtica vida ética.

La era del zoón hedonikón (subfenotipo del zoón poietikón que reemplazara evolutivamente al zoón noetikón bifacial) augurada por la primacía ontológica del mundo sensible sobre el inteligible. El deicidio nietzscheano no es el motivo embrional, lo es la elevación del mundo sensible sobre el suprasensible por rechazo del símbolo, objeto de faz ad supra alienada del lógos en su meta-intencionalidad, en favor del icono que nutre el epílogo, la faz epilógica del alienado lógos monofacial, ordenada al epifenómeno de ser. Toda la imaginería alienante de una techné absorta en su propio lógos interno, como una moderna liturgia de la inmanencia que el cine refleja (alardes de tecno-logía abducente del espectador, promesas de un futuro sin límites, predios de dominio y progreso). La intrahistoria imposible en un mundo fascinado por una techné sustraída a cualquier forma crítica o ralentizadora de lógos externo, obedeciendo únicamente a sus propios códigos binarios en simbiosis con falacias mercantilistas. La 
tecnología marca el ritmo de desarrollo social, abortando el tiempo de sedimentación que exige la intrahistoria, sin espacios de disidencia, una corriente global que todo lo engulle o lo arrastra vertiginosamente pues en el horizonte de sucesos de un agujero negro, en las postrimerías de una cultura, el tiempo se dilata, el dispar latido de los relojes newtoniano (era del yo) y relativista (era del ello). El tiempo del epílogo se expande.

Si el supra-egocidio que supone la adnihilatio mística en una atmósfera pandémica (el Dios de la teología racionalista ha desatendido a su criatura, consumida en el oscuro regazo de la Peste Negra, la desmedida verticalidad de su voz, intrincada trama de pináculos estabilizadores de fuerzas oblicuas de los arbotantes, ábsides y capillas radiales, su estilizada razón gótica -Sumas de tortuosa geometría, laberintos de argumenta pro et contra, prodigiosas catedrales hendidas por la tenebrosa luz dionisiana-, no le ha rozado, silente ante su drama, sólo cabe una desesperada solución cordial por completo desasimiento -unio mystica: el Homo theophanicus se interna en su Dios mudo para enterrarse con él-) allana el terreno al renacimiento: el espacio natural abierto frente a la lúgubre clausura de la catedral (el humanismo incipiente libera a la dañada criatura de la oscuridad, la insta a la luz; el neoplatonismo resurgente simplifica la luz como sublimación de lo divino, superfluos los muros en favor de los vanos, éstos acogen la luz física que conformará el renovado espacio, no la dócil y difusa luz concentrada en puntos-aleph, adulterada por juegos de vidrieras y rosetones que transforman el espacio en irreal y simbólico), la phýsis redescubierta (fisiocentrismo) como ámbito de celebración (y ulterior divinización) de un hombre nuevo, que comienza a ensimismarse (antropocentrismo), a instalarse en el intra se, lugar de gestación del yo, demacrada la facies supra se por viraje idealista. La entropía de la misma subjetividad que prospera a expensas del acre corion teológico la torna finalmente un astro masivo que entrará en fase de colapso gravitatorio, con una elevada tasa de pérdida de materia yoica, inflación egológica por iludización psíquica (ello), ingentes cantidades de tegumentos remanentes de egogénesis expelidos a su alrededor, una enana azul muy convectiva incapaz de sostenerse por la presión de degeneración de los electrones que perece lentamente, víctima de su inercia racional. Una alta velocidad de rotación intrínseca depara pérdidas irreparables de simetría yoica, la creciente "metalicidad" de la razón enfría al astro marchito, la gran descompensación entre presión hidrostática y gravedad implanta una escala de tiempo dinámica (no térmica) en la que la subsistencia bajo determinada luminosidad ya no se rige por las reservas de energía potencial gravitatoria. Extinto el ideal absoluto de la razón, el yo agoniza al compás de la desintegración de su intrahistoria, transido por tensiones ídicas que desgarran su matriz, se torna una enana negra, y el oscuro agujero 
postremo es la expresión vestigial del yo macilento, aplastado por su propia gravedad. La lógica sorda y borrosa de la revolución utópica se desvanece en esa bóveda. Los modelos personalistas son inviables sobre una ética de mínimos o sobre éticas de consenso. La personalidad no es un grado ontológico adicional, aun último, sino que eleva al individuo por encima de sus contingencias ontológicas, individualidad incluida, lo redefine en el atrio supra-ontológico de la dignitas por adhesión voluntaria a un sistema de valores a modo de referencial inercial ya no vigente. El horizonte de la persona es el de la ultima solitudo en el que todo condicionante ha caído y sólo impera la autodeterminación volitiva sobre la que el individuo conquista su identidad ... ¿Cómo podría darse esa situación en una era alienada de predominio de fuerzas ilúdicas, flujos subterráneos no amortiguados de vida estética, narcisismo, necesidad de satisfacción inmediata y cultura fisionada (embozos de la provechosa y brutal especialización), minifundios de vida fragmentaria, de identidades fracturadas (fractura no genética, inducida por concurso de ambiguas fuerzas externas imbricadas en la dinámica social que escapan al área ontológica de influjo de endebles egos)?

No se han perdido los marcos referenciales de actuación, como señala Taylor, sólo ha cambiado su carácter, aun en la democratización del ámbito transcendental de existencia por repulsa de cualquier forma de vida como lugar privilegiado de lo sagrado ${ }^{5}$. La mediación del símbolo decae por contacto directo con la transcendencia signada; la significación secundaria se hace superflua, vana, el icono agota toda representación cuando la transcendencia se desacraliza por transferencia al sujeto de esa condición (sujeto transcendental). La mecánica que rige la vida social es relativista, no newtoniana, adopta referencias no inerciales de construcción de subjetividad bajo claves de equivalencia. Y en esas esferas no inerciales de actuación y autorrealización subjetiva eclosiona lo reprimido en la epimorfosis alienada del yo, elevado hacia el en-sí como un pináculo flamígero, expresión del declive de una razón ofuscada, sobrecargada de abalorios, que ya no es capaz de vislumbrar su motivo primordial, difuminado bajo el álgebra de las palabras, apenas episodios melancólicos de impaciencia ante el misterio que pugnan por aniquilarlo, derrocado el aparato sobrenatural de causas ${ }^{6}$. Voces ansiosas por extender su herrumbre sobre él. Miríadas de voces osadas, animadas por la llamada democrática a (re)crear, a opinar, a transgredir, sin la lenta maduración que exigen el entusiasmo y la vigilancia de la conciencia (auto-)crítica, impúdicas, desordenas, en un afán de notoriedad individual, próxima, ante la ausencia de un sentido más sosegado de transcendencia.

5 Charles Taylor, Fuentes del yo. La construcción de la identidad moderna (Barcelona: Paidós,1996), 232.

6 Peter L. Berger, Una gloria lejana (Barcelona: Herder, 1994), 42ss. 
Imposible en ese tumulto de voces, en la hipnosis bajo el vértigo exergónico de los avances tecnológicos, forjar intrahistoria.

La sintaxis hipomórfica del ello bajo la ajada máscara morfológica del yo. No hay libertad donde hay alienación. Una voluntad sonámbula no podría ser una voluntad libre, sino enajenada. La alienación de la inmanencia despunta en los disfraces del ello: el yo sólo es una exuvia fláccida para el ello emergente, una cutícula mórbida que camufla los predicados ilúdicos inervantes ... "Yo quiero", "Yo deseo"... Autosatisfacción, bienestar a ultranza, conjura de pródromos patéticos que reclamen tediosos símbolos transcendentes, la meta-significatividad del símbolo no podría sino estar truncada para un lógos monofacial. La pulsión biófaga del ello bajo la envoltura egológica, una corriente vadosa egopénica que anuncia al ello, en la que se transluce la matriz psíquica instintiva (el efecto Coriolis de las pasiones psíquicas subyacente siempre en la egosfera se intensifica). Los tenues colores aposemáticos del yo, la individualidad autosuficiente, la plena autonomía intelectual egomórfica del "sapere aude", encubriendo el imperio emboscado del ello, el mimetismo batesiano de la era ilúdica, abonada al orden sensible, sólo asistido por ese debilitado yo en un juego de asesorías y secuestros ${ }^{8}$ para la gestión de culturas a la medida (el Estado no se retrae para dejar al hombre concreto construir su identidad ${ }^{9}$, hay una eugenesia encubierta en esa falsa retirada, en forma de hipnopedia, que dicta los cauces de emergencia y residencia al ello con sus éticas de convergencia).

La metafísica no podría ser nunca un lenguaje meta-empírico de símbolos al servicio de la alienación transcendente, a diferencia de una epistemología de primeras intenciones, el lenguaje de signa rerum en que consista la ciencia y su red de conexiones lógicas, juicios sintéticos solidarios a relaciones causales a partir de intuiciones sensibles. Más allá del fenómeno como rédito psíquico del procesado de datos empíricos sobre intuiciones y categorías puras, el símbolo hace presente de forma figurada la realidad, la re-presenta, no en norma intelectiva o psíquica, sino espiritual, la redimensiona en ese orden de ser. Una

7 Horacio brinda a la posteridad los tópicos basales de la era del yo bifacial ("Dimidium facti, qui coepit, habet: sapere aude, incipe" -Epístolas I, 2-) y el ello monofacial ("Carpe diem, quam minimum credula postero" -Odas I, 11-). Este último tópico, esencial como exhortación al primum vivere, desnaturalizado, sin embargo, en el theatrum mundi de la era ilúdica. Atrás, el lema central de la era del super-yo: "Noli foras ire, in te ipsum redi, in interiore homine habitat veritas, et si tuam naturam mutabilem inveneris, transcende et te ipsum" (el "transcende et te ipsum" transluce la acusada basculación ad supra de un lógos bifacial en proyección supra-egomórfica).

8 Zygmut Bauman, Keith Tester, La ambivalencia de la modernidad y otras conversaciones (Barcelona: Paidós, 2002), 144: "el juego de las asesorías y los secuestros se prolonga indefinidamente: lo empuja la ansiedad generada por la soledad y por la inadecuación que una vida vivida individualmente [ilúdicamente] no puede sino fomentar".

9 Zygmut Bauman, Identidad (Madrid: Losada, 2005), 40ss. 
donación simbólica no es una donación real, sino una mediación: el símbolo no es tanto el disfraz de pulsiones reprimidas que explora Freud cuanto el significante de una conciencia colectiva que se aliena en el preciso instante en que lo sacraliza como vehículo de contacto con lo transcendente, sobrevaluando un simple medio de manifestación del espíritu humano configurador de universo cultural (la suma de modos simbólicos de su propia realidad en que cada hombre consista, según Cassirer) que lícitamente sólo puede reflejar la nostalgia de una estancia paradisíaca, la de alguna quimera ausente (Beyle o el poeta que extrajera la luz del hogar de los rayos primitivos y jamás mordiera la tierra y los inframundos).

\section{SÍMBOLO E ICONO: META- Y EPI-POSICIÓN INTENCIONAL DEL SIGNO}

Símbolo e icono son alienantes posiciones supra- e infra-intencional del signo. Bajo segunda significación (connotativa, ya no denotativa, no directamente deyectiva en el fenómeno de ser), el signo es medium alienandi (la adaliedad inherente del signo, stare pro alio, le expone a la amenaza de la alienación en su meta-significatividad por tracción trans- o epifenoménica del aliud que expide). Como símbolo queda revestido de un valor sacramental alienante, sirviendo de vector meta-cognitivo a la faz ad supra de la inteligencia, sugestionada en una ansiosa demanda de verdad, travestida en faz epistémica la que sólo es faz idealizadora o práctica con reflejo real en el tejido social.

El símbolo conmina en su indumento o densidad sacramental a una dimensión suprasensible de realidad, sobredimensión del fenómeno de ser como metafenómeno de ser. El símbolo es el vicario nouménico de la era del super-yo, tomado "voov́ $\mu \varepsilon v o v "$ en su prístina acepción kantiana: el "en-sí" inabordable, límite de intuición sensible, sólo virtual objeto de intuición suprasensible o in-

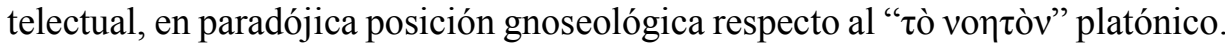
Extramuros, fuera de experiencia posible, sin abordaje en el ámbito del conocimiento por desbordar formas puras de la sensibilidad (espacio-tiempo) y del entendimiento (categorías), la recodificación de tò noetón como noúmeno es el preámbulo a la subvertida preferencia de mundos, sensible sobre inteligible, inaugural de la era del ello: detracción de inteligibilidad a lo inteligible por excelencia en el universo suprasensible platónico, los arquetipos noéticos o eidéticos del mundo superior, transfigurados desde el pensamiento cristiano en ideas ejemplares en la mente divina por asimilación del kósmos noetós al noûs creador, ideas que sustentaran durante siglos la universalidad ante rem. El paradigma de inteligibilidad en el dualismo cósmico del ateniense (noetón) “degenera" en 
noúmeno, dimensión trans-inteligible (más que ininteligible) del ser en su ensidad, con la consiguiente pérdida de cotización epistémica, monopolizada por el

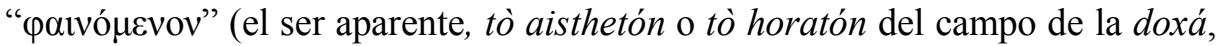
revierte su indigencia ontológica izado en genuino objeto epistémico), de modo que la facies ad supra (ordenada al noúmeno ahora) pierde esa competencia, deja de detentar la función epistémica que alienta la expectativa de supraegomorfosis por abono al preeminente mundo eidético, friso de verdades eternas.

He ahí el desajuste entre las eras de lógos bifacial: faz ad supra epistémica (era del super-yo) / no epistémica, sólo idealizadora (era del yo); con todo, la ficción incondicionada que se transparenta en el noúmeno es crucial en la regulación de los usos de la razón (si la inteligibilidad imputa al entendimiento, sólo lo susceptible de experiencia posible lo sería, el noúmeno se descuelga como meta-inteligible, tal declaración no socava su racionalidad, el noúmeno será ideal racional -razón pura-, mas no objeto inteligible -entendimiento- por deficiencia humana de intuición intelectual). La carga alienante del kósmos noetós

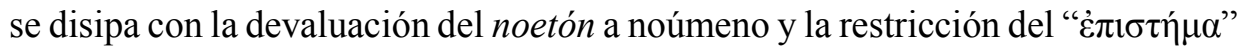
a fenómeno, sin declinar el vigor canónico que conserva aún su posición supra -ya no externa al alma-, espejismo gnoseológico cardinal de postulados de razón práctica (la transvaluación del noetón como nooúmenon promueve su interiorización en la razón práctica, fomentando una ética formal contra las éticas materiales clásicas -epicúrea, cristiana, ...-; la última, en particular, asimila el noetón platónico a idea exemplaris in mente divina praexistens, regida la ética humana por fines extrínsecos a la razón: si el kósmos noetós era exterior a la mente humana, subsistente en sí mismo o contraído al entendimiento divino, el cosmos nouménico es intrapsíquico, y el ideal ético, interno a la razón). Finalmente, el desmoronamiento de ese mundo frente al sensible despejará la escena a un lógos unifacial. El símbolo como vector nouménico o elemento de fuga de fenómeno a noúmeno es emisario de una ficción sémica, transmisor de una fantasía alienante que invita a transcender el fenómeno de ser, cuando el ser de fenómeno sólo es fundamento meta-ontológico del fenómeno de ser, no una faceta del mismo de raíz transcendente, insinuando un estadio egomórfico sublimado ( $s u$ per-yo) filial a ese reino superior (la meta-fenomenalidad está vinculada al ser de fenómeno, recuérdese, amparando a la metafísica, ficticio el metafenómeno de ser que hubiera de fundarse en un ser de metafenómeno, por ser la metafenomenalidad requisito de la misma fenomenalidad del ser; la metáfora ontológica permitirá elevar la ontología -fenómeno de ser- a la meta-ontología o meta-fenomenología en que pueda convertirse la metafísica). El ser de metafenómeno sería objetivo de una metafísica simbólica: ontología, lenguaje de 
signos; metafísica sacramental, lenguaje de símbolos en la era de alienación transcendental

Como icono, el signo en epi-posición intencional destina a una dimensión epifenoménica del ser polarizadora de la faz ad infra de la inteligencia en flexión alienante. El icono recodifica el fenómeno de ser al que apunta la intencionalidad directa o primera significatividad del signo como epifenómeno de ser, esto es, en clave objetiva estimulante del ello. Una subdimensión del fenómeno de ser apta o atractiva a la vida psíquica estético-instintiva: el fenómeno de ser, objeto ontológico por excelencia, reconducido epifenoménicamente como figura de una estética basal que aglutina necesidades vitales de pulsión ilúdica, aliciente de la vida primaria del psiquismo individual, atrapado en una vigilia sensitiva, sometido a un constante estímulo de inmanencia. Como piso orgánico, la era icónica se alza sobre una cartografía ruinosa de símbolos desvitalizados.

Si la metafísica clásica, en forzada cadencia sobre el quiasmo áxico-categorial que denuncia Nietzsche (contraposición en conflicto de valores y categorías de raigambre superior a las regentes en la imagen del mundo terreno, los errores dogmáticos del espíritu puro y el bien en sí que sostriban la moral contranatural cristiana y su reinvención del kósmos noetós platónico), es meta-lógos del símbolo que connota el ser de meta-fenómeno (estática ontología tradicional que desdeña en la depreciada apariencia al fenómeno de ser, naufragio en el istmo insalvable entre ser real y ser aparente), una metafísica lacerada por íntimos prejuicios contra la vida, lastrada por antítesis a las categorías vitalistas (horror a la muerte, a la vejez, la idea de Dios como suprema "objeción contra la vida, contra la existencia""10), la exacerbada pasión vital que consume al ello será un dilatado epílogo (epi-lógos) articulado sobre signos epimórficos (epimorfismo icónico, desviación epi-intencional de función denotativa del signo): el ser en su faz icónica, epifenoménica, en inmediata disposición a la satisfacción del ello (la caverna tiene avidez de espacio, preconiza Saramago, ofreciendo el secreto de la inmanencia: acumular vísperas, el suave vaivén de la vida estética, hasta la víspera de nada, siquiera del viaje a ningún lugar).

El eikón, sombra sensible, cifra un índice de apertura a un sentido de lo nouménico completamente distinto al que reporta el símbolo en su vectorialidad metacognitiva. El símbolo es el vehículo de alienación epistémica, un ficticio conocimiento que capitula en el metafenómeno de ser como objetivo imaginal $\mathrm{y}$, a posteriori, suscita una propensión volitiva a él (nihil volitum nisi

10 Friedrich Nietzsche, Crepúsculo de los ídolos (Madrid: Alianza, 1972), 49-50: "Las razones por las que este mundo ha sido calificado de aparente por el metafísico, fundamentan, antes bien, su realidad: otra especie de realidad diferente es absolutamente indemostrable". 
praecognitum: el asentimiento agustiniano -cum assensione cogitare- a credibilia, somáticos en principio -la fe anida en los sentidos en un primer momento, el creyente la recibe a través de esos canales-, acaece cuando estos han sido procesados racionalmente, deviniendo rationabilia, y da forma así al acto fideico -fides formis o formata-). El icono, por el contrario, es primordialmente vector de alienación volitiva, más que epistémica, pues incita a la dimensión epifenoménica del ser en la que el ello psíquico desvela su semblante como instancia psíquica convocada a ese valor práctico del noúmeno. La hegemonía de lo nouménico sobre lo fenoménico impone la verdad práctica (hábito de la verdad para el ello) sobre la gnoseológica (sustitución del dictum "nihil volitum quin praecognitum" por la máxima heterodoxa "nihil cognitum quin praevolitum"), subordinación del entendimiento a la voluntad, si bien a una voluntad informe seducida (cercada) por sombras. El viejo apotegma de verdad como acomodación del intelecto a la cosa se torna cláusula de adecuación propósito resultado: "verdad es lo que moviéndonos a obrar de un modo u otro haría que cubriese nuestro resultado o nuestro propósito", dirá Unamuno ${ }^{11}$; la conciencia es una patología genética, la enfermedad mortal que aqueja al hombre, diferenciándole del resto de animales, y la existencia, una kénosis apo-syneidética, "salir fuera de sí" para contemplarse patéticamente como ser expósito, salir de la intimidad de la conciencia haciéndose objeto de sí mismo (en esa problemática distancia respecto a sí reposa la angustiosa experiencia de la propia conciencia y del tiempo que sólo la intrahistoria logra apaciguar como sustrato permanente del devenir, realidad eterna que sustenta el presente y el curso fáctico externo, alma del tiempo que el vértigo de la era del ello anula), con una dialéctica subrepticia de la utopía y la contra-utopía no instauradora ya del contravoluntarismo que revalida (recuperación de lucidez por el héroe patético) el precepto "nihil volitum quin praeintellectum" abandonado. La prioridad de la razón vital patética (trófica) en la que se adivina al ello travestido de yo sobre el intelecto ("nihil cognitum quin praevolitum"). El conocimiento se encauza a través de la verdad práctica irracional a la satisfacción de un anhelo - necesidad vital. Facetas psíquicas cognitiva y volitiva coordinadas en el estado paradisíaco. Irrupción de la razón, contención de la deriva instintiva, deflación del noúmeno, alienación por tensión razón - sentimiento: impotencia de la razón ante lo espiritual (inaccesible via rationis). La realidad en sí (dimensión nouménica) sería entonces irracional, demandando una solución de compromiso distinta, la senda patética del sentimiento y el instinto, este es fundamento de todo conocimiento: el 'hambre de Dios' de la era de alienación transcendente es, en la era del ello, hambre - tendencia instintiva a lo nouménico que crepita en la intimidad

11 Miguel De Unamuno, Del sentimiento trágico de la vida (Madrid: Escelier, 1966), 130. 
psíquica, agotado en inmanencia ex corde, lejos del delirio racional de un zoôn noetikón. La arrogancia del ego cogitans idealizador cede a la turbación de un ego volens / nolens irreverente, más bien un ego desiderans por la insoslayable racionalidad intrínseca del auténtico acto volitivo ... Ego desiderans remedium animae meae, casi una opaca plegaria.

La función transponente (no supra-ponente o epi-ponente del ser) de la metáfora ontológica y su carácter de fenómeno cotidiano, elude el peligro de infracción del servicio a la vivencia original que pudiera entrañar el proceso de conceptualización, metaforesis canalizada, en la crítica del filósofo de Röcken, por conjuntos de metáforas intuitivas que la costumbre fija, encubierta en la génesis conceptual la acción racional conducente a las fijaciones de límite que definen un mundo noético abstracto como contrapunto al mundo de intuiciones primordiales. La infiltración en la cotidianeidad de la metáfora ontológica pudiera ser, en algunas de sus formas, una delación del contacto furtivo con el noúmeno, la experiencia inferencial o intuitiva de lo absoluto-noumenal que posibilita su mención (línea de la crítica idealista postkantiana), que hace plausible hablar de él al margen de la negada intuición metafísica, no sensible.

El concepto elaborado sobre la metáfora ontológica, por más que simule referirse al ser de fenómeno, no pierde de vista el fenómeno de ser que confiere cariz ontológico a la metáfora, ésta sólo procura una transposición, tiende un puente entre fenómeno de ser y ser de fenómeno, sin meta- o epifenomenalizar al ser como harían símbolo o icono. El proceso de sustancialización de realidades singulares a través de la metáfora ontológica que imbuye la vida cotidiana previene el riesgo que advierte Nietzsche de alumbramiento de la verdad como trama de generalizaciones e ilusiones impuestas por el uso, haciendo inmanente la metafísica a la vida común. Si el olvido de la naturaleza metafórica del concepto es la principal "precaución" (omisiva) contra el devenir del ser como fenómeno, esa aspiración taimada en la representación a la captura del eidos autárquico sobre el supuesto epistemológico de que el concepto no recorte arbitrariamente las articulaciones de la realidad, no basta la actitud estética que reniegue de formas puras de sensibilidad e inteligencia o de toda correspondencia lógica entre los órdenes subjetivo y objetivo, abocada al saber efímero y creativo a tenor del ser como devenir ${ }^{12}$. La metáfora ontológica proporciona ese enlace entre el puro devenir del ser (fenómeno de ser) y un fundamento para él que, aun de plena cobertura ontológica como fenómeno, sin ángulos oscuros o zonas ónticas refractarias a la fenomenalización, sin franjas opacas de inmutabilidad, no se agote en ninguna concreta manifestación, asegurando así la constancia del 
devenir. Ese puente subtendido por la metáfora, nexo transpositivo entre fenómeno de ser (ontología) y ser de fenómeno, mantendría viva una metafísica que, superada la adicción al símbolo o previsora de la abrasiva detonación de los iconos, hiciera de aquella figura su instrumento (una metafísica combativa en los epitopos del signo).

\section{METÁFORA ONTOLÓGICA}

Nietzsche afirma que la verdad es una ilusión alienante (la ilusión en un sujeto que ha olvidado que lo es), una coalescencia de metáforas desvaídas, gastadas, metonimias y antropomorfismos referentes de relaciones humanas reducidos al metal en que fueron acuñados ${ }^{13}$. La primacía de la metáfora sobre la literalidad late en textos de Ricoeur y Gadamer, no es algo novedoso, pero es el valor de fenómeno (cognitivo) de vida cotidiana que Lakoff le reconoce, rescatada de la marginalidad retórica que la desterrase secularmente del lenguaje cognitivo relegándola al emotivo, el que sugiere una pujante instrumentalidad metafísica para ella, ya no simple renta de acción poética sino núcleo de construcción de significado.

Contra la teoría sustitutiva de la metáfora y sobre la hipótesis basal de la impregnación por ella, no sólo del lenguaje o el pensamiento (y en él, la propia cosmovisión, la concepción humana del mundo), también de la acción o cualquier manifestación de vida cotidiana, el cognitivismo reemplaza los nodos significativos por campos o lienzos semánticos, sin exigencia de descodificación específica de las proyecciones metafóricas. La alquimia cuántica del significado en "orbitales" sémicos, mapeos semánticos intersectantes ${ }^{14}$ con distinción de dominios meta o fuente para las imágenes representativas.

En la teoría de interacción de rasgos, la pulsión significativa de la fórmula metafórica es rédito interactivo de dos elementos concertados bajo una lógica conectiva difusa ${ }^{15}$. La anfisbenia esquemática de la metáfora, su efecto relacional, hará de ella el puente ideal de conexión discursiva del fenómeno de ser (objeto ontológico en dominio fuente de experiencia cotidiana) y su fundamento

13 Friedrich Nietzsche, "Sobre verdad y mentira en sentido extramoral", Cuadernos Teorema 36 (1980): 11 .

14 George Lakoff, Mark Johnson, Metáforas de la vida cotidiana (Madrid: Cátedra, 1995), 67: "Las metáforas ontológicas, con ser tan naturales, impregnan tanto nuestro pensamiento que normalmente se consideran descripciones directas y autoevidentes de fenómenos mentales. A la mayoría de nosotros nunca se nos ocurre pensar que son metafóricas".

15 Max Black, Modelos y metáforas (Madrid: Tecnos, 1966); I. A. Richards, The Philosophy of Rethoric (Oxford: Oxford Clarendon Press, 1936). 
óntico, dominio más abstracto, inaccesible a la inmediata cognición, hacia el que fluye la metafísica. El nivel de abstracción que puede alcanzar la metáfora la avala como matriz temática de variación de multitud de actos lingüísticos, si bien la impregnación metafórica de la cotidianeidad alza a esa figura en algo más que la pálida evidencia lingüística de un fenómeno, un objeto comprendido, o una acción: en ella coligan dos dominios conceptuales, germinando por combinación de "rasgos [semánticamente] incompatibles"16. El interés periférico que despertara tradicionalmente, subrayado por Lakoff, cede a su ponderación como un producto genético-estructural de nóesis sobre el que descansa en buena medida la actividad conceptualizadora, no un simple recurso lingüístico sino una figura integrada en la articulación categorial de la experiencia vital (la metáfora es fruto de variaciones asociativas categoriales y su ubicuidad debilita las aproximaciones estrictamente lógico-semántica o sintáctica de generativistas).

Si la metáfora orientacional, en la clasificación de Lakoff, organiza extrarelacionalmente un sistema global ("la esencia de la metáfora es entender y experimentar una cosa en términos de otra" ${ }^{17}$ por cruzamiento preferencial de dominios conceptuales correlativos, permeando así lenguaje, pensamiento y acción), la metáfora ontológica categoriza de modo peculiar un fenómeno, sustancializado o procesado como entidad. La metáfora ontológica contraería cualitativamente acontecimientos, emociones, ideas, ..., resaltando su entidad, su calidad sustancial. Abstractas nociones son metafóricamente sustancializadas, maniobra que permite la cuantificación subsidiaria de dominios meta (fenómenos). Parte del mosaico conceptual está metafóricamente conformado o ensamblado, numerosos conceptos se articulan, al menos parcialmente en su constitución, en relación a otros (la potencia cognitiva de la metáfora radica en su virtud transpositiva de lo concreto a lo abstracto: actos psíquicos complejos, abstractas experiencias subjetivas, se conceptualizan desde campos basales de experiencia por intencionalidad tética en clave vectorial metafórica) ${ }^{18}$. Nociones emergentes en la experiencia corpórea se sostienen sobre metáforas espaciales que brindan ocasión conceptual a las emociones (la metáfora es mapa conceptual de dominios cruzados: relaciones de entrecruzamiento entre dominios destino de experiencia sensitiva y dominios origen de experiencia corpórea que facultan a la metáfora como vehículo cognitivo ${ }^{19}$, influjo sensorio-motor en la diagénesis

16 M. Victoria Escandell, Introducción a la pragmática (Barcelona: Ariel lingüística, 1996), 189.

17 George Lakoff, Mark Johnson, Metáforas de la vida cotidiana, 41.

18 María J. Cuenca, Joseph Hilferty, Introducción a la lingüistica cognitiva (Barcelona: Ariel lingüística, 1999), 39: "las categorías se forman por la intersección de una o varias propiedades típicas que tienden a coincidir, aunque dicha coincidencia no sea estrictamente necesaria".

19 George Lakoff, Mark Johnson, Philosophy in the Flesh. The Embodied Mind and Its Challenge to Western Thought (New York: Basic Books, 1999), 45-48. 
conceptual por metaforización de afecciones desde dominios concretos de sensismo).

\section{INSTRUMENTALIDAD METAFÍSICA DE LA METÁFORA ONTOLÓ- GICA}

Frente a la meta- o la epi-dimensión del fenómeno por vectorialidad sobreo infra-intencional del signo, será misión de la metafísica la preservación de un escenario de no alienación desde la reducción de la ontología a fenomenología, sin solapamiento de fenómeno de ser y ser de fenómeno. Negación de la metafenomenalidad del ser que salve la alienación transcendente, y prevención, a la vez, contra la epi-fenomenalidad del ser que atenúe la alienación de la era ídica.

La eficacia operativa de la metáfora estriba en su cometido traslativo ( $\mu \varepsilon \tau \alpha-$

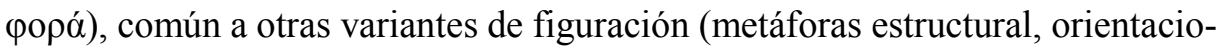
nal, ...), restringida por específica comisión ontológica (fenómeno de ser). Esa modalidad de metáfora no incurre en una segunda significación en la que la forzada meta-intencionalidad simbólica o redirección transversal al ser de metafenómeno del signo pudiera crear el espejismo (gnoseológico) de un conocimiento transcendental, mal de la era del lógos bifacial en la que la facies ad supra alentara la esperanza de un destino intuitivo superior expedita en el símbolo. Elude el descenso a pasadizos metasémicos, la fuga hacia el ser de metafenómeno, eficiente en simple transposición sustancial de dominios fenoménicos concretos (remonta el hiato entre fenomenalidad y onticidad del fenómeno, sin redimensión meta-ontológica: la metáfora de esa índole se ciñe a los dominios de la experiencia vital, sustancializándolos, no infundiéndoles la apariencia de una conexión transcendental, sino transportándolos a un plano de significación en el que devengan su nuda onticidad). No excede la función ideativa del lenguaje (Halliday), participando en la determinación del mundo como entorno ontológico del sujeto y en la estructuración de su cosmovisión. El contenido simbólico del signo en segunda significación oculta a menudo una aspiración al noúmeno, como si el símbolo fuera un subterfugio para paliar el déficit de intuición intelectual que, a juicio de Kant, impidiera al hombre el acceso epistemológico al en-sí. La metáfora ontológica no entra en comunión con él, lo conjura por reducción del en si a fundamento óntico de fenómeno de ser.

Matizado el enfoque de Lakoff, en el que la metáfora ontológica tendría una potente carga analógica (escalas lineales -estar o ser "más allá" ...-, mecanicismo o somatización psíquica -maquinalidad metafórica de la mente-, o referencia física de la vida interior), subsumida en la metafísica quedará desprovista de ella, 
inhibida esa suplementaria tara analógica por su aplicación sobreyectiva. La metáfora ontológica proyecta parciales dominios meta en un dominio fuente, en terminología de Lakoff que se modulará aquí: sobreyección de dominios fenoménicos (ontológicos) en un dominio óntico puro por sustancialización, a la manera en que los diferentes términos de una sucesión matemática son reunidos o sobreyectados en un término general que, por tal, no tiene expresión fenoménica (su consistencia es netamente óntica) o no se abate en ninguna de sus singulares manifestaciones, sin reservas a una plena ontologización, o al modo en que la esencia sólo anuda idealmente las existencias concretas que la encarnan, sin realidad en sí como esencia, pero sin ser concretamente ninguna de ellas. Es metáfora ontológica porque transpone (phéro) más allá (metá) del dominio físico-ontológico (fenomenológico) al óntico puro, sin concreción en cuanto tal, meta-físico únicamente en el sentido de inagotado en ninguna singular fenomenalidad, límite en todo escrutinio cognitivo de la realidad, en cualquier censo ontológico (la ensidad de la cosa es límite porque queda fuera del error fenomenológico solidario al examen del para-sí en su coyuntura ontológica), "más allá" (metá) de toda concreción fenoménica sólo como trasfondo óntico inextinguible, como potencialidad constante a manifestaciones ulteriores. Depurada de carga analógica, por ser la analogía relación inyectiva entre dominios fenoménicos, no sobreyección de dominio fenoménico (meta) a óntico puro (dominio fuente de Lakoff).

Objeto, sustancia, causa ... ideas censuradas por el empirismo, son conceptos forjados a la luz de la percepción por el sujeto de su misma entidad separada, una auto-delimitación ontológica que cobra expresión metafórica. La Lebenswelt, la esfera de subjetividad transcendental, accesible tras la epojé fenomenológica y la reducción eidética, desde la que el yo funda el mundo, está estructurada metafóricamente. El papel de la metáfora es decisivo en la consolidación de intenciones subjetivas y su posible objetivación reflexiva, en la percepción temática de objetos por su egotropismo (encuadrados en la tendencia hacia el yo) o en la "representación ponente (setzenden Vergegenwärtigung) neutralizada". La posición tética, no dóxica, de la fantasía, por déficit de posicionalidad del contenido de la vivencia (la fantasía se distinguirá de la modificación de neutralidad por desdibujada distinción de actos tético y dóxico en esta última) recusa la vehicularidad cognitiva de la metáfora. Las vivencias de fantasía y de percepción neutralizadas, indiscriminables una vez sus contenidos y estructuras de correlación noético-noemáticas hayan sido modificadas "en tanto 
que neutrales", esas sombras de actos $^{20}$, no han de sustentarse en metáforas ontológicas.

Ejemplo de de la metáfora ontológica en una línea metafísica de discurso: un ecosistema es un mural vivo, una comunidad de organismos en interacción asentada en un medio físico configurado por factores abióticos (agentes geomorfológicos, condiciones climáticas, ...) y por el propio influjo de la biocenosis, en cuyo seno se establecen asociaciones intra- e interespecíficas, con flujos de materia y energía en las cadenas tróficas. Un ontosistema o sistema óntico es una sociedad de seres interrelacionados que definen un campo óntico (ontokenosis: vaciamiento fenoménico del ser en un marco de interconexión). El escenario de apertura ontológica del ser como fenómeno de ser es un ontotopo, y en él concurren factores ontogénicos y antigénicos con sus adyuvantes. Las relaciones translucen tropismos ontológicos, flujos de ser en una precaria homeostasis amenazada por la entropía.

\section{CONCLUSIÓN}

Si el símbolo o el icono son paradigmas de una alienada fuga metafísica o antimetafísica hacia la segunda intencionalidad del signo, desvirtuación alienante (connotación) de su valor supositivo o denotativo, la metáfora ontológica es exponente de la presencia de lo metafísico en la cotidianeidad: el elemento metafísico se revela presente en la vida cotidiana a través de la metáfora ontológica, esto es, a través de la significatividad ontológica del signo en clave metafórica. En su función denotativa (orientada al fenómeno de ser), el signo es figura ontológica o fenomenológica, la ciencia es lenguaje de signos. En su vigor connotativo, es símbolo o icono. En incepción metafórica, no es connotativo sino transpositivo, su intencionalidad y su significación primera no se han plusvaluado por desviación de referencia al fenómeno de ser en beneficio del metafenómeno o el epi-fenómeno de ser al que arrastra su virulencia connotativa, sólo se ha recodificado la intendencia denotativa con visado metafórico conectivo de fenómeno (objeto ontológico) y ser de fenómeno (fantasma metafísico). La metafísica es lenguaje de signos en su nervio denotativo (no de símbolos o iconos, por tanto), reforzado metafóricamente (un paso más allá de la simple diligencia denotativa en que el signo se escorza como figura onto-epistemológica). 
La metafísica eficaz no ha de prestar servicio al símbolo como canal de alienación transcendente, tampoco al icono, escolio de naufragio en la inmanencia, coartada toda ilusión transcendente. La primera es la metafísica antinatural que sancionara Nietzsche en su fuga meta-fenoménica o nouménica, la segunda es la vía de la orfandad metafísica por olvido del ser en la fuga epifenoménica del icono. La servidumbre al signo desfigurado por meta-intencionalidad es lesiva para la metafísica, al hilo de la distinción ser de fenómeno / fenómeno de ser, y sin concesión al meta-fenómeno de ser por expresa profesión del ser de fenómeno como fundamento de fenomenalidad, debe guiarse sobre el signo en su primera significación, en declinación ontológica, no en su meta/epi-intencionalidad simbólica o icónica. La sola posibilidad del uso metafórico de la intencionalidad ontológica del signo apelativo al ser de fenómeno da tonalidad metafísica a la cotidianeidad.

\section{REFERENCIAS BIBLIOGRÁFICAS}

Bauman, Zygmut. Identidad. Madrid: Losada, 2005.

Bauman, Zygmut, Keith Tester. La ambivalencia de la modernidad y otras conversaciones. Barcelona: Paidós Ibérica, 2002.

Berger, Peter L. Una gloria lejana. Barcelona: Herder, 1994.

Cuenca, María J., Joseph Hilferty. Introducción a la lingüistica cognitiva. Barcelona: Ariel lingüística, 1999.

Davidson, Donald. "What Metaphors Mean". Critical Inquiry 5 (1978): 31-47.

Escandell, M. Victoria. Introducción a la pragmática. Barcelona: Ariel lingüística, 1996.

Husserl, Edmund. Philosophie als strenge Wissenschaft. Frankfurt am Main: Klostermann Texte, 1965.

Kurzon, D. Discourse of Silence. Amsterdam: John Benjamins, 1998.

Lakoff, George, Mark Johnson. Metaphors We Live By. Chicago: Chicago University Press, 1980 (edición en español, Metáforas de la vida cotidiana, Madrid: Cátedra, 1986).

-. Philosophy in the Flesh. The Embodied Mind and Its Challenge to Western Thought. New York: Basic Books, 1999.

Lawler, J. M. "Review of Lakoff's and Johnson's Metaphors We Live By". Language 59 (1983): 201-207.

Llamas, Vicente. El lógos bifacial. Las sendas de Éros y Thánatos. MadridPorto: Sindéresis, 2015.

-. "Poíesis y alienación en la dialéctica materialista". Carthaginensia 68 (2019): 443-483. 
Lycan, William G. Philosophy of Language: A Contemporary Introduction. New York: Routledge, 1999.

McGinn, Colin. Basic Structures of Reality: Essays in Meta-Physics. Oxford: Oxford University Press, 2011.

Nietzsche, Friedrich. Crepúsculo de los ídolos. Madrid: Alianza, 1972.

Nuessel, Frank H. "Review of Lakoff's and Johnson's Metaphors We Live By". Lingua 56 (1982): 185-200

Shibles, W. Editor. Metaphor: An Annotated Bibliography and History. Whitewater (WI): Language Press, 1971.

Strawson, Peter F. Entity and Identity. Oxford: Oxford University Press, 1997.

Taylor, Charles. Fuentes del yo. La construcción de la identidad moderna. Barcelona: Paidós, 1996.

Van Noppen, J. P., E Hols,. Editores Metaphor II. A Classified Bibliography of Publications 1985 to 1990. Amsterdam: Benjamins, 1990.

Violi, P. "Review of Lakoff's and Johnson's Metaphors We Live By". Journal of Pragmatics 6 (1982): 189-194.

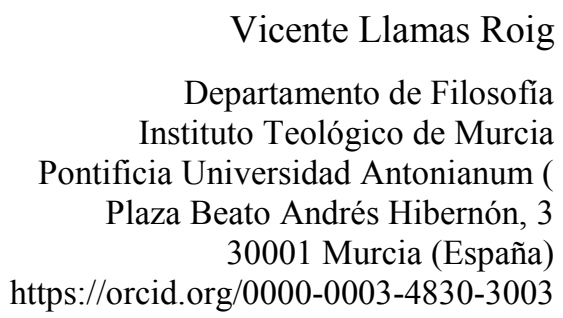

